\title{
SYNTHESIS OF AMINOARENETHIOLATO-COPPER(I) COMPLEXES
}

A.<smiles>CCNCc1ccccc1</smiles>

2. $1 / 8 \mathrm{~S}_{8}, \mathrm{THF},-80^{\circ} \mathrm{C}$ to $-20^{\circ} \mathrm{C}, 2.5 \mathrm{~h}$

3. $\mathrm{Me}_{3} \mathrm{SiCl},-20^{\circ} \mathrm{C}$ to rt, $2.5 \mathrm{~h}$

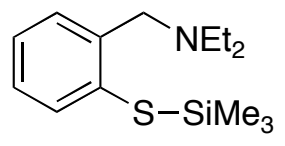

B.

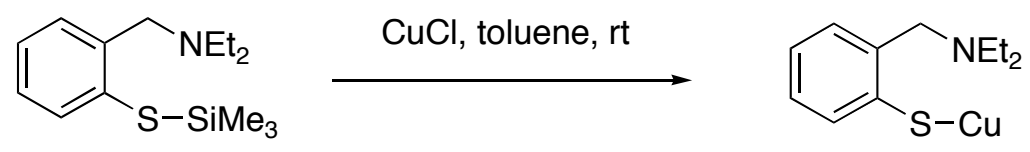

Submitted by Elena Sperotto, Gerard P.M. van Klink and Gerard van Koten. ${ }^{1}$

Checked by Karla Bravo-Altamirano and Peter Wipf. ${ }^{2}$

\section{Procedure}

A. Diethyl(2-[(trimethylsilanyl)sulfanyl $]$ benzyl)amine. A flame-dried, 250-mL Schlenk tube (Note 1), containing a magnetic stir bar, equipped with a rubber septum and a nitrogen inlet is charged with benzyldiethylamine $(6.00 \mathrm{~g}, 36.7 \mathrm{mmol})$ (Note 2). The flask is cooled in a dry ice-acetone bath to $-78{ }^{\circ} \mathrm{C}$ (temperature of the bath is checked with a thermometer, internal temperature is not monitored) (Note 3) and anhydrous, degassed pentane (80 $\mathrm{mL}$ ) (Notes 4,5 ) is added by syringe. A solution of $t$-butyllithium in pentane (1.7 M, $23.8 \mathrm{~mL}, 40.4 \mathrm{mmol}, 1.1$ equiv) (Note 6) is added dropwise by syringe over $5 \mathrm{~min}$, and the reaction mixture is maintained at $-78{ }^{\circ} \mathrm{C}$ for another $1.5 \mathrm{~h}$. The mixture is slowly allowed to reach room temperature with stirring over $16 \mathrm{~h}$. The solution is concentrated in vacuo at $0.01 \mathrm{mmHg}$. Cold anhydrous, degassed THF ( $70 \mathrm{~mL}$ at $-78{ }^{\circ} \mathrm{C}$, kept in a dry ice-acetone bath) (Notes 5,7 ) is added by syringe to the Schlenk tube which is immersed in a cold bath at $-78{ }^{\circ} \mathrm{C}$. Sublimed sulfur (1.296 g, $40.43 \mathrm{mmol}, 1.1$ equiv) (Note 8 ) is added to the reaction flask by temporarily removing the septum (Note 9). The reation mixture is maintained at a bath temperature of $-78{ }^{\circ} \mathrm{C}$ for 2 $\mathrm{h}$, then the reaction mixture is allowed to slowly warm (by adding acetone to the cooling bath) to about $-20{ }^{\circ} \mathrm{C}$ (temperature of the bath). Chlorotrimethylsilane ( $9.8 \mathrm{~mL}, 77.2 \mathrm{mmol}, 2.1$ equiv) (Note 10) is added over $1 \mathrm{~min}$ by syringe and the mixture is stirred for another $2 \mathrm{~h}$ while slowly 
warming up to room temperature. The solvent is then removed in vacuo at $0.01 \mathrm{mmHg}$ and the residue is re-dissolved in anhydrous, degassed hexanes $(50 \mathrm{~mL})$ (Notes 4, 5). The solvent is then removed in vacuo at $0.01 \mathrm{mmHg}$, the residue is re-dissolved in hexanes $(50 \mathrm{~mL})$, and precipitation of $\mathrm{LiCl}$ is observed. The suspension is transferred to a flame-dried, $100-\mathrm{mL}$ centrifuge vessel via cannula (Note 1), and is separated from the precipitated $\mathrm{LiCl}$ by centrifugation ( $7 \mathrm{~min}, 28,000 \mathrm{rpm}$ ). A suitable alternative to centrifugation is Schlenk filtration or any other technique that allows manipulation under inert atmosphere. Finally, the hexane supernatant is removed by cannula into a flame-dried, 100-mL Schlenk tube (Note 1). The solution is concentrated in vacuo at $0.01 \mathrm{mmHg}$ to afford $9.32 \mathrm{~g}(95 \%)$ of the product as a yellow oil (Note 11).

B. 2-[(Diethylamino)methyl]benzene thiolato-copper(I). A flamedried, 100-mL Schlenk tube (Note 1), containing a magnetic stir bar, is equipped with a rubber septum and a nitrogen inlet, and is charged with diethyl(2-[(trimethylsilanyl)sulfanyl]benzyl)amine $(2.32 \mathrm{~g}, 8.69 \mathrm{mmol})$. Anhydrous, degassed toluene $(20 \mathrm{~mL})$ (Notes 5,12$)$ is added by syringe resulting in a yellow solution. A second flame-dried 100-mL Schlenk tube (Note 1), containing a magnetic stir bar, equipped with a rubber septum and a nitrogen inlet, is charged with $\mathrm{CuCl}(0.774 \mathrm{~g}, 7.82 \mathrm{mmol}, 0.9$ equiv) (Note 13) and anhydrous, degassed toluene $(20 \mathrm{~mL})$, to provide a white suspension. The thiolate solution is transferred by cannula to the suspension of $\mathrm{CuCl}$ and the mixture is stirred under nitrogen until the reaction mixture is clear and free from visible solids (Note 14). The solvent is removed at 0.01 $\mathrm{mmHg}$, anhydrous, degassed hexanes $(50 \mathrm{~mL})$ (Notes $4,5,15)$ is added and the reaction mixture is vigorously stirred. The solution is transferred to a flame-dried, 100-mL centrifuge vessel (Note 1) by cannula and separated

from the precipitate by centrifugation ( $7 \mathrm{~min}, 28,000 \mathrm{rpm}$ ). Finally, the hexanes solution is removed by cannula. The precipitate is dried in vacuo at $0.01 \mathrm{mmHg}$ to give the product as a fine off-white powder $(1.63 \mathrm{~g}, 6.32$ mmol, $81 \%$ ) (Note 16).

\section{Notes}

1. The apparatus is first flame-dried under vacuum (using an inert gas manifold with a mercury bubbler) and once it cools to room temperature, it is placed under an atmosphere of nitrogen and carefully maintained under 
this atmosphere during the entire course of the reaction because the product is highly air and moisture sensitive.

2. Benzyldiethylamine was purchased from TCI America at $\geq 98 \%$ purity and vacuum-distilled $\left(60{ }^{\circ} \mathrm{C}, 2 \mathrm{mmHg}\right)$ before use. The submitters purchased benzyldiethylamine from Acros Organics and used it as received.

3. The submitters performed the reaction using a liquid nitrogenethanol bath at $-80{ }^{\circ} \mathrm{C}$.

4. $n$-Pentane was purchased from Acros Organics at $99+\%$ purity, and hexanes (technical grade) was purchased from Fischer Scientific. Both solvents were distilled under nitrogen over calcium hydride before use. The submitters purchased pentane and hexane from Interchema and distilled them under nitrogen over sodium sand.

5. All anhydrous solvents used in the procedure were freeze-thaw degassed (4 cycles) prior to use.

6. $t$-Butyllithium (1.7 $\mathrm{M}$ in pentane) was used as received from Sigma Aldrich. The submitters obtained $t$-butyllithium (1.5 $\mathrm{M}$ in pentane) from Acros Organics.

7. THF was obtained from Alfa Aesar at $99+\%$ purity and distilled under nitrogen over sodium benzophenone ketyl. The submitters purchased THF from Sigma Aldrich and distilled it under nitrogen over sodium sand.

8. Sulfur (99.50\%, sublimed) was purchased from Acros Organics and used as received. The submitters obtained sulfur from Sigma Aldrich (powder 100 mesh, sublimed) and used it as received.

9. The sulfur is added in a single portion via the use of weighing paper. The submitters found it more convenient to add the sulfur in a small glass container, which is dropped into the reaction mixture.

10. Chlorotrimethylsilane (TMSCl) was purchased from Sigma Aldrich at $\geq 99 \%$ purity, distilled under nitrogen from quinoline (TMSCl/quinoline, 9:1) $\left(\mathrm{T}=57^{\circ} \mathrm{C}\right)$ and stored over $4 \AA$ molecular sieves. The submitters purchased TMSCl from Acros Organics, distilled it under nitrogen and stored it over activated $4 \AA$ molecular sieves.

11. The product displayed the following physicochemical properties: ${ }^{1} \mathrm{H}$ NMR (400 MHz, $\mathrm{C}_{6} \mathrm{D}_{6}$ ) $\delta: 0.13$ (s, 9H, SSi $\left.\left(\mathrm{CH}_{3}\right)_{3}\right), 0.94$ (t, $6 \mathrm{H}, J=7.0$ $\left.\mathrm{Hz}, \mathrm{N}\left(\mathrm{CH}_{2} \mathrm{CH}_{3}\right)_{2}\right), 2.44$ (q, $\left.4 \mathrm{H}, J=7.0 \mathrm{~Hz}, \mathrm{~N}\left(\mathrm{CH}_{2} \mathrm{CH}_{3}\right)_{2}\right), 3.85(\mathrm{~s}, 2 \mathrm{H}$, $\left.\mathrm{CH}_{2} \mathrm{~N}\right), 6.92(\mathrm{~m}, 1 \mathrm{H}, \mathrm{ArH}), 7.10(\mathrm{~m}, 1 \mathrm{H}, \mathrm{ArH}), 7.44(\mathrm{~d}, 1 \mathrm{H}, J=7.40 \mathrm{~Hz}$, $\mathrm{ArH}), 7.73$ (d, $1 \mathrm{H}, J=7.8 \mathrm{~Hz}, \mathrm{ArH}) ;{ }^{13} \mathrm{C} \mathrm{NMR}\left(100.5 \mathrm{MHz}, \mathrm{C}_{6} \mathrm{D}_{6}\right) \delta: 1.5$ $\left.\left.\left(\mathrm{SSi}\left(\mathrm{CH}_{3}\right)_{3}\right), 12.9\left(\mathrm{NCH}_{2} \mathrm{CH}_{3}\right)_{2}\right), 47.9\left(\mathrm{NCH}_{2} \mathrm{CH}_{3}\right)_{2}\right), 57.2\left(\mathrm{CH}_{2} \mathrm{~N}\right), 127.1$ (Aryl $C$ ), 127.8, 130.3, 131.5, 136.9, 144.9. Because of the high air and 
moisture sensitivity of the compound, no elemental analysis or GC-MS analysis could be obtained. Preparation of NMR samples under a nitrogen atmosphere (NMR tube kept in a Schlenk tube during preparation) allows NMR analysis and determination of purity of the sample. The solvent $\mathrm{C}_{6} \mathrm{D}_{6}$ was distilled under nitrogen over calcium hydride at $80{ }^{\circ} \mathrm{C}$, stored over activated $4 \AA$ molecular sieves and freeze-thaw degassed prior to use.

12. Toluene was obtained from Fischer Scientific (99.9\%) and was distilled under nitrogen over sodium benzophenone ketyl. The submitters purchased toluene from Interchema and distilled it under nitrogen over sodium sand.

13. $\mathrm{CuCl}$ was freshly prepared and kept under nitrogen according to the following procedure: To a preheated solution of $\mathrm{CuSO}_{4} \cdot 5 \mathrm{H}_{2} \mathrm{O}(99.9 \mathrm{~g}$, $0.40 \mathrm{~mol}$ ) and $\mathrm{NaCl}(25.96 \mathrm{~g}, 0.40 \mathrm{~mol}, 1$ equiv) in $400 \mathrm{~mL}$ of water at 65 ${ }^{\circ} \mathrm{C}$ (oil bath temperature) is slowly added over $1.5 \mathrm{~h}$ an aqueous solution of $\mathrm{NaOH}$ (14.40 g, 0.36 mol, 0.9 equiv) and $\mathrm{NaHSO}_{3}(22.89$ g, $0.22 \mathrm{~mol}, 0.55$ equiv). The mixture is stirred for $1 \mathrm{~h}$ and the temperature is kept between 65 and $70{ }^{\circ} \mathrm{C}$. After being cooled, the reaction mixture is transferred under nitrogen onto a $250-\mathrm{mL}$ Schlenk-type filter funnel (25-50 $\mu \mathrm{m}$ porosity) where the solid is washed with: an aqueous solution of acetic acid $(1 \mathrm{~mL}$ in 1 $\mathrm{L}$ of water), an aqueous solution of $\mathrm{NaHSO}_{3}(1 \mathrm{~g}$ in $1 \mathrm{~L}$ of water), acetone (800 mL), technical diethyl ether $(1 \mathrm{~L})$, pre-dried (on $\mathrm{KOH})$ diethyl ether $(1$ L) and dry diethyl ether $(1 \mathrm{~L})$. Very important: always keep the solid under a layer of solvent, and never in contact with air! The resulting solid is then transferred into a pre-dried Schlenk tube and dried under vacuum, to afford copper(I) chloride as a white powder $(31.7 \mathrm{~g}, 0.32 \mathrm{~mol}, 80 \%)$. This reagent must be stored under an atmosphere of nitrogen.

14. The reaction time may vary from 2 to $4 \mathrm{~h}$. Under a strictly air-free manifold, a suitable alternative is to allow the reaction to proceed overnight.

15. Hexanes were used to remove all soluble impurities.

16. The product is slightly air sensitive and is stored under a nitrogen atmosphere. The product displayed the following physicochemical properties: ${ }^{1} \mathrm{H}$ NMR $\left(400 \mathrm{MHz}, \mathrm{C}_{6} \mathrm{D}_{6}\right) \delta$ : $0.99(\mathrm{t}, 6 \mathrm{H}, J=7.0 \mathrm{~Hz}$, $\left.\mathrm{N}\left(\mathrm{CH}_{2} \mathrm{CH}_{3}\right)_{2}\right), 2.44$ (q, $\left.4 \mathrm{H}, J=6.3 \mathrm{~Hz}, \mathrm{~N}\left(\mathrm{CH}_{2} \mathrm{CH}_{3}\right)_{2}\right), 3.68$ (br s, $2 \mathrm{H}$, $\left.\mathrm{CH}_{2} \mathrm{~N}\right), 6.78(\mathrm{~d}, 1 \mathrm{H}, J=7.0 \mathrm{~Hz}, \mathrm{ArH}), 6.88(\mathrm{t}, 1 \mathrm{H}, J=7.0 \mathrm{~Hz}, \mathrm{ArH}), 7.02$ $(\mathrm{t}, 1 \mathrm{H}, J=7.0 \mathrm{~Hz}, \operatorname{Ar} H), 7.91(\mathrm{~d}, 1 \mathrm{H}, J=7.4 \mathrm{~Hz}, \operatorname{Ar} H) ;{ }^{13} \mathrm{C}$ NMR $(100.5$ $\left.\mathrm{MHz}, \mathrm{C}_{6} \mathrm{D}_{6}\right) \delta: 11.4\left(\mathrm{~N}\left(\mathrm{CH}_{2} \mathrm{CH}_{3}\right)_{2}\right), 49.9\left(\mathrm{~N}\left(\mathrm{CH}_{2} \mathrm{CH}_{3}\right)_{2}\right), 61.6\left(\mathrm{CH}_{2} \mathrm{~N}\right), 124.0$ (Aryl C), 127.9, 132.7, 135.5, 136.4, 143.3; Anal. Calc. for $\mathrm{C}_{11} \mathrm{H}_{16} \mathrm{CuNS}$ : C, 51.24; H, 6.25; N, 5.43; Found: C, 50.57; H, 6.24; N, 5.33. Although the 
combustion data for carbon is outside the acceptable range, it is the best result obtained by the checkers.

\section{Safety and Waste Disposal Information}

All hazardous materials should be handled and disposed of in accordance with "Prudent Practices in the Laboratory"; National Academy Press; Washington, DC, 1995.

\section{Discussion}

Copper(I)-mediated reactions have recently become the choice for large industrial scale applications, since copper is environmentally friendly and cheaper than other transition metals already explored. However, most organocopper compounds still present several limitations including the sensitivity towards moisture and air, the low solubility in organic solvents and the thermal instability. Many studies were performed trying to improve the activity and selectivity of copper-catalyzed reactions. ${ }^{3}$

One of the problems met with copper-catalyzed reactions is the solubility of the catalyst, which influences the catalytic activity and often requires the use of high temperatures and/or harsh reaction conditions. Improvements can be found, using additives or external ligands or solvents, which render the copper salts more soluble, allowing the use of milder reaction conditions. ${ }^{4,5}$ An obvious solution to these problems is the synthesis of welldefined copper complexes, which are soluble in a broad range of solvents.

The procedure reported herein describes the synthesis of such a welldefined copper(I) complex in which a copper(I) cation is bonded to a monoanionic, potentially $S, N$-bidentate coordinating amino-thiolate ligand. The synthesis proceeds through a three-step procedure; the first step involves the heteroatom assisted ortho-lithiation of the arene to the corresponding organolithium compound. In the second step, the insertion of sulfur into the lithium-carbon bond of the aryllithium reagent affords the in situ preparation of the corresponding lithium arenethiolate. Subsequent reaction with chlorotrimethylsilane gives the trimethylsilyl-protected arenethioether, which then is reacted with $\mathrm{CuCl}$ in toluene to afford the desired copper(I) arenethiolate complex.

A set of modified complexes (Fig.1) can be synthesized by changing the diethylamino functionality for, i.e., dimethylamino, pyrrolidinyl, piperidinyl or 
morpholinyl substituents. Diverse substituents can be introduced directly onto the aromatic ring (i.e. TMS, $t$-Bu, $\mathrm{CF}_{3}, \mathrm{OMe}$ ) and a naphthalene backbone can be used instead of a benzene unit.

These well-defined copper(I) complexes ${ }^{6}$ exhibit good thermal stability and solubility in common organic solvents. In addition, electronic and physical properties can easily be fine tuned by introducing substituents at the arene ring or the amino-functionality. ${ }^{7}$

Figure 1. Selected examples of copper(I) aminoarenethiolates.
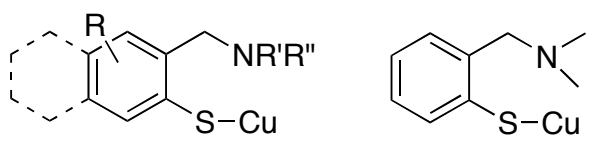

$86 \%^{\mathrm{a}}$

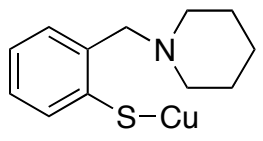

${ }^{a}$ overall yields of steps $A, B$

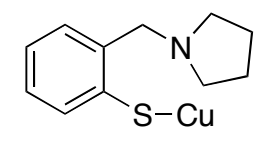

$75 \%^{\mathrm{a}}$

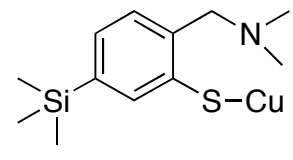

$91 \%^{\mathrm{a}}$

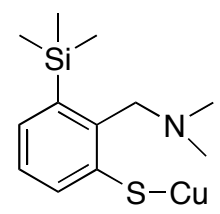

$95 \%^{\mathrm{a}}$

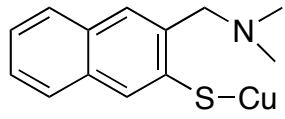

$70 \%^{\mathrm{a}}$

Characterization of copper(I) aminoarenethiolates by NMR and X-ray crystal structure determination, both in solution and in the solid state, showed highly aggregated species (trimers, tetramers or even nonamers). ${ }^{8}$ The molecular structure is generally based on a core comprising a sixmembered cyclohexane-like $\mathrm{Cu}_{3} \mathrm{~S}_{3}$ ring, with alternating copper and sulfur atoms. The sulfur atom of each of the arenethiolate ligands bridges two copper atoms while the trigonal coordination geometry at each copper atom is attained by intramolecular $\mathrm{N}-\mathrm{Cu}$ coordination. ${ }^{7}$

These copper-aminoarenethiolates have already been tested as catalyst (precursors) in allylic substitution, ${ }^{9}, 1,4-^{10}$ and $1,6-^{11}$ addition reactions, aromatic $\mathrm{N}^{12}$ and $\mathrm{O}_{-}{ }^{13}$ arylation reactions, and have shown excellent catalytic properties (Figure 2).

Taking into account the actual performances and activities of these copper complexes, and their wide range of applicability, they can be considered as a useful and versatile tool in organic synthesis, and a valid soluble replacement of the common, insoluble copper(I) halide salts. 


\section{Figure 2. Application examples of aminoarenethiolato-copper(I) catalyzed reactions.}

allylic substitution

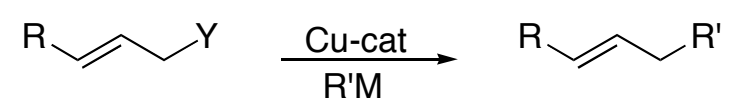<smiles>[R]C([R])C=C</smiles>

1,4-addition reaction

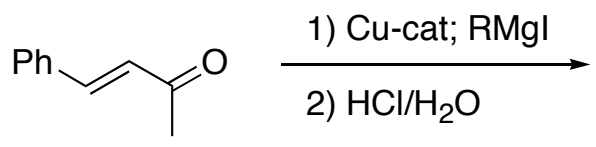<smiles>[R]C(CC(C)=O)c1ccccc1</smiles>

1,6-addition reaction

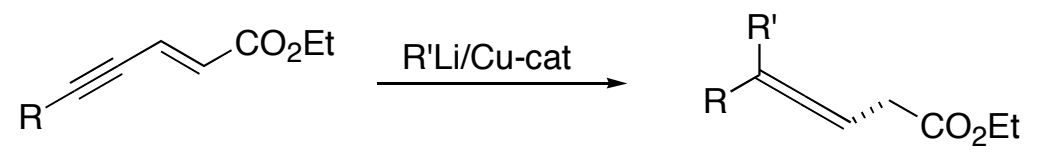

$N$-arylation
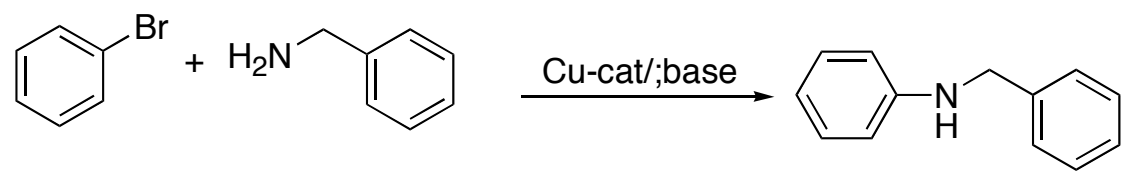

O-arylation<smiles>Brc1c[R]ccc1</smiles><smiles>Oc1ccc(F)cc1</smiles>

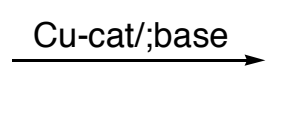<smiles>[R]c1ccc(Oc2ccccc2)cc1</smiles>

1. Organic Chemistry and Catalysis, Utrecht University, Padualaan 8, 3584 CH, Utrecht, The Netherlands. E-mail: g.vankoten@uu.nl

2. Department of Chemistry, University of Pittsburgh, Pittsburgh, PA 15260, USA.E-mail: pwipf@pitt.edu.

3. Ley, S. V.; Thomas, A. W. Angew. Chem. Int. Ed. 2003, 42, 5400-5449.

4. Beletskaya, I. P.; Cheprakov, A. V. Coord. Chem. Rev. 2004, 248, 2337-2364.

5. Kunz, K.; Scholz, U.; Ganzer, D. Synlett. 2003, 15, 2428-2439.

6. Posner, G. H.; Whitten, C. E.; Sterling, J. J. J. Am. Chem. Soc. 1973, 95, 7788-7800.

7. Knotter, D. M.; van Maanen, H. L.; Grove, D. M.; Spek, A. L.; van Koten, G. Inorg. Chem 1991, 30, 3309-3317.

8. Janssen, M. D.; Grove, D. M.; van Koten, G. Prog. Inorg. Chem. 1997, 46, 97-149.

9. (a) Persson, E. S. M.; van Klaveren, M.; Grove, D. M.; Bäckvall, J.-E.; van Koten, G. Chem. Eur. J. 1995, 1, 351-359; (b) van Klaveren, M.; Persson, E. S. M.; del Villar, A.; Grove, D. M.; Bäckvall, J.-E.; van Koten, G. Tetrahedron Lett. 1995, 36, 3059-3062; (c) Meuzelaar, G. J.; 
Karlström, A. S. E.; van Klaveren, M.; Persson, E. S. M.; del Villar, A.; van Koten, G.; Bäckvall, J.-E. Tetrahedron 2000, 56, 2895-2903; (d) van Klaveren, M.; Persson, E. S. M.; Grove, D. M.; Bäckvall, J.-E.; van Koten, G. Tetrahedron Lett. 1994, 35, 5931-5934.

10. (a) Arink, A. M.; Braam, T. W.; Keeris, R.; Jastrzebski, J. T. B. H.; Benhaim, C.; Rosset, S.; Alexakis, A.; van Koten, G. Org. Lett. 2004, 6, 1959-1962; (b) van Klaveren, M.; Lambert, F.; Eijkelkamp, D. J. F. M.; Grove, D. M.; van Koten, G. Tetrahedron Lett. 1994, 35, 6135-6138; (c) Lambert, F.; Knotter, D. M.; Janssen, M. D.; van Klaveren, M.; Boersma, J.; van Koten, G. Tetrahedron Asymmetry 1991, 2, 1097 1100; (d) Knotter, D. M.; Grove, D. M.; Smeets, W. J. J.; Spek, A. L.; van Koten, G. J. Am. Chem. Soc. 1992, 114, 3400-2410.

11. Haubrich, A.; van Klaveren, M.; van Koten, G.; Handke, G.; Krause, N. J. Org. Chem. 1993, 58, 5849-5852.

12. Jerphagnon, T.; van Klink, G. P. M.; de Vries, J. G.; van Koten, G. Org. Lett. 2005, 7, 5241-5244.

13. Sperotto, E.; Jerphagnon, T.; van Klink, G. P. M.; de Vries, J. G.; van Koten, G. In preparation.

\section{Appendix}

\section{Chemical Abstracts Nomenclature (Registry Number)}

t-Butyllithium: (594-19-4)

Sulfur; (7704-34-9)

Trimethylsilyl chloride: Silane, chlorotrimethyl-; (75-77-4)

Copper chloride: Cuprous chloride; (7758-89-6) 


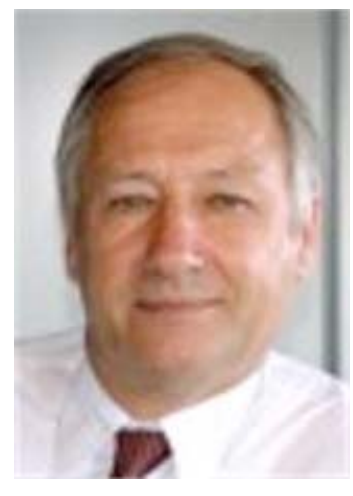

Gerard van Koten retired in September 2007 and was appointed Emeritus Professor. $\mathrm{He}$ is currently active as Distinguished University Professor of Utrecht University and Distinguished Research Professor University of Cardiff (UK). $\mathrm{He}$ is known for his research on XCX-pincer metal complexes. The preparation and use of the first examples of homogeneous metallodendrimer catalysts demonstrate his interest for supramolecular systems with (organometallic) catalytically active functionalities. Recent developments involve the introduction of the XCX-pincer metal units in polypeptide chains, carbohydrates and in the active site of serine hydrolases. Currently systems are under development for cascade catalysis, which is connected to his interest in the development of sustainable (green) chemistry.

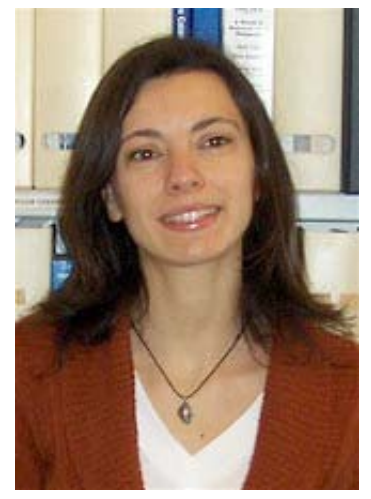

Elena Sperotto was born in 1978 in Sandrigo, Italy, and studied chemistry at the University of Padova where she received her Master degree in 2003. Afterwards, she spent one year at DSM Research in Geleen, The Netherlands, for a post-graduate research project on enzymatic resolution of amino acids. Since October 2004, she is working on her Ph.D. thesis at Utrecht University under the supervision of Prof. G. van Koten and she currently investigates copper-catalyzed carbon-heteroatom coupling reactions.

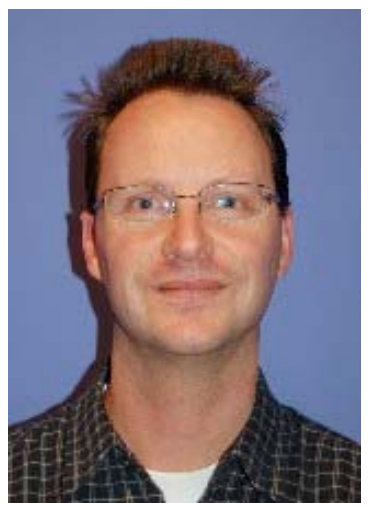

Gerard van Klink (27.8.1966) completed his Ph.D. under the supervision of Prof. F. Bickelhaupt at the Vrije Universiteit Amsterdam. He worked as a post-doctoral fellow on the design and synthesis of co-catalysts for Ziegler-Natta polymerization processes, and on low-valent catalysts for olefin polymerization in the group of Prof. J. Eisch at the State University of New York at Binghamton. From 1998 until 2007 he had a position as assistant professor in the Department of Organic Chemistry and Catalysis headed by Prof. G. van Koten. Presently, he is working in the field of metal-organic frameworks at the Delft University of Technology. 


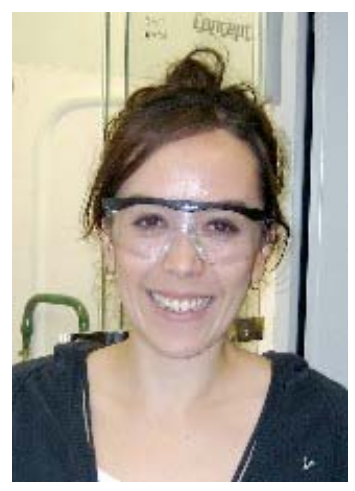

Karla Bravo-Altamirano obtained a B.S. degree in Chemistry in 2002 from Universidad de las Americas in Puebla, Mexico, where she conducted research under the supervision of Prof. Cecilia Anaya. She obtained her Ph.D. in 2007 from Texas Christian University with Prof. Jean-Luc Montchamp. Her research focused on the development of catalytic methodologies for the synthesis and functionalization of $\mathrm{H}$ phosphinic acid derivatives and their $P$-chiral counterparts. Currently, she is a postdoctoral research associate in the group of Prof. Peter Wipf at the University of Pittsburgh where she is working on the dynamic combinatorial library generation as well as on the synthesis of suppressors of the peroxidase activity of cyt $c /$ TOCL complexes and PKD inhibitors. 